\title{
Comparison of an Electronic Nose Based on Ultrafast Gas Chromatography, Comprehensive Two-Dimensional Gas Chromatography, and Sensory Evaluation for an Analysis of Type of Whisky
}

\author{
Paulina Wiśniewska, Magdalena Śliwińska, Tomasz Dymerski, \\ Waldemar Wardencki, and Jacek Namieśnik \\ Department of Analytical Chemistry, Faculty of Chemistry, Gdan'sk University of Technology, \\ 11/12 Narutowicza St., 80-233 Gdańsk, Poland
}

Correspondence should be addressed to Paulina Wiśniewska; p.m.wisniewska@gmail.com and Tomasz Dymerski; tomasz.dymerski@gmail.com

Received 7 October 2016; Revised 19 December 2016; Accepted 18 January 2017; Published 5 March 2017

Academic Editor: Lee Y. Heng

Copyright (C) 2017 Paulina Wiśniewska et al. This is an open access article distributed under the Creative Commons Attribution License, which permits unrestricted use, distribution, and reproduction in any medium, provided the original work is properly cited.

Whisky is one of the most popular alcoholic beverages. There are many types of whisky, for example, Scotch, Irish, and American whisky (called bourbon). The whisky market is highly diversified, and, because of this, it is important to have a method which would enable rapid quality evaluation and authentication of the type of whisky. The aim of this work was to compare 3 methods: an electronic nose based on the technology of ultrafast gas chromatography (Fast-GC), comprehensive two-dimensional gas chromatography $(\mathrm{GC} \times \mathrm{GC})$, and sensory evaluation. The selected whisky brands included 6 blended whiskies from Scotland, 4 blended whiskies from Ireland, and 4 bourbons produced in the USA. For data analysis, peak heights of chromatograms were used. The panelists who took part in sensory evaluations included 4 women and 4 men. The obtained data were analyzed by 2 chemometric methods: partial least squares discriminant analysis (PLS-DA) and discrimination function analysis (DFA). E-nose and GC $\times$ GC allowed for differentiation between whiskies by type. Sensory analysis did not allow for differentiation between whiskies by type, but it allowed giving consumer preferences.

\section{Introduction}

Whisky is an alcoholic beverage produced by the distillation of malted or fermented grain mash. Whisky is matured in oak barrels of a capacity not exceeding $700 \mathrm{l}$. Only water and pure caramel, a natural colorant, can be added to the distillate [1-3]. Scotch whisky is the most popular alcoholic drink of this type, which, in addition to all the above-mentioned requirements, has to be exclusively produced in Scottish distilleries. Scotch whisky is mainly produced from barley malt, water, and an admixture of some grains, for example, wheat and rye.

Irish whisky is made in Ireland and, as in the case of Scotch, it also consists of malted barley and some grains. The taste of Irish whisky is more delicate than that of Scotch, because the former is obtained by 3 separate distillations [4]. Besides those described above, one of the most popular types of American whisky should be mentioned, namely, bourbon. Bourbon must fulfill the following requirements established by the US Congress in 1964:

(i) It has to be prepared from a mix of grains containing at least $51 \%$ corn (maize).

(ii) The distillate must contain no more than $80 \%$ pure alcohol.

(iii) It has to be only made from natural ingredients.

(iv) It has to be rested in new oak barrels that are charred inside. 
(v) It cannot be poured into the barrels if the content of pure alcohol in the distillate exceeds $62.5 \%$.

(vi) It has to be produced in the United States of America.

In general, bourbon is made from a mash containing $70 \%$ corn, wheat or rye, and malted barley. The mash undergoes fermentation which is followed by distillation and maturation. Due to the fact that resting is a very important stage of bourbon production, most bourbon brands specify the duration of the aging period on the label of the product. During the resting period, whisky develops its color and woody flavor. The longer the resting period, the darker the color $[5,6]$.

In the case of raw material, whisky can be divided into 2 groups. One is made partly from corn, such as bourbon; the second is produced without corn, such as Irish or Scotch whisky. Apart from botanical origin, it is important to analyze a whisky for its type of production. Irish and Scotch whisky are produced from the same raw materials, but in different ways. The main difference is triplicate distillation in the case of Irish whisky.

The composition of whisky is most frequently analyzed by means of one-dimensional gas chromatography [7-9]. More advanced analyses are conducted by employing twodimensional gas chromatography [10]. Besides the 2 aforementioned techniques, liquid chromatography [11], spectroscopy $[12,13]$, sensory evaluation [14], and sensor-based electronic nose [15] are also used for this purpose. Such broad diversity of applied analytical techniques is related to the complex composition of available whisky products. Whisky is also analyzed to control its composition and quality as well as authenticate the brand. Distinguishing between the whisky brands in relation to the production procedure, product origin, and quality can be provided by using an electronic nose based on the technology of ultrafast gas chromatography, comprehensive two-dimensional gas chromatography, and sensory analysis.

Comprehensive two-dimensional gas chromatography $(\mathrm{GC} \times \mathrm{GC})$ is a technique used for the separation of complex mixtures of chemical compounds and their identification. In comparison to one-dimensional gas chromatography, it allows for the detection of a larger amount of compounds and reduction of the risk of coelution; unfortunately, it is also very expensive.

The electronic noses are analytical tools designed to detect and identify mixes of aromatic substances by mimicking the mode of action of the human olfactory organ. To this day, specific chemical sensors are mainly used. However, at present, e-noses based on mass spectrometry and fast gas chromatography are also applied [16]. The electronic nose, based on Fast-GC, combines the advantages of both the aforementioned chromatographic technique and an electronic nose. This allows for obtaining comprehensive information about the sample composition and the volatile fraction profile [17]. In comparison to GC $\times$ GC, analysis by using e-nose based on Fast-GC is cheaper and less time-consuming, but there is no possibility of detecting so many compounds included in the matrix [18].
Sensory evaluation is mainly used for the quality assessment of products. This type of analysis allows investigating the preferences of consumers and, in comparison to other techniques, it is the cheapest one. However, due to the presence of people, it can be considered as the least objective analysis.

In this work, the suitability of an electronic nose based on the technology of ultrafast gas chromatography, comprehensive two-dimensional gas chromatography, and sensory evaluation for the analysis of whisky was tested. The criteria of whisky selection were botanical origin and way of production. The aim of this work was to compare the 3 types of analysis. The whisky market is highly diversified, and because of this, it is important to invent a method which would enable a rapid quality evaluation and authentication of a whisky sample. For data analysis, we tested such chemometric methods like partial least squares with discriminant analysis (PLS-DA) and discriminant function analysis (DFA).

\section{Materials and Methods}

2.1. Materials. Only samples purchased in local stores in Gdańsk (Poland) were used in the study. The selected whisky brands included 6 blended whiskies from Scotland, 4 blended whiskies from Ireland, and 4 bourbons. All samples had been matured for 3 years. Among the samples were whiskies in different price ranges.

2.2. Sample Preparation. All samples used in the analysis by e-nose and GC $\times$ GC-TOFMS were processed according to the same analytical procedure. An aliquot of $1.75 \mathrm{ml}$ of whisky was diluted with $6.25 \mathrm{ml}$ of deionized water. Next, in the case of analysis by the electronic nose, the sample was mixed and incubated at $40^{\circ} \mathrm{C}$ for $20 \mathrm{~min}$. A sample prepared in this manner was analyzed in triplicate. In the case of GC $\times$ GCTOFMS, samples were prepared by using headspace solid phase microextraction (HS-SPME). A sample prepared in this manner was analyzed in duplicate. In the case of sensory analysis, each panelist received $20 \mathrm{ml}$ of sample in a glass. The general scheme of procedures for sample preparation and analysis is shown in Figure 1.

2.3. GC $\times$ GC-TOFMS Analysis. For solid phase microextraction, divinylbenzene/carboxen/polydimethylsiloxane (DVB/ CAR/PDMS) fiber was used. Thermostating was carried out for $5 \mathrm{~min}$ at $40^{\circ} \mathrm{C}$. Extraction was carried out for $20 \mathrm{~min}$ at $40^{\circ} \mathrm{C}$, and desorption was carried out for $20 \mathrm{~min}$ at $250^{\circ} \mathrm{C}$.

The GC $\times$ GC system consisted of an Agilent 6890 gas chromatograph (Agilent Technologies, Palo Alto, CA, USA) equipped with a liquid nitrogen-based single-jet dual-stage cryogenic modulator and a split/splitless injector, coupled with a Pegasus III time-of-flight mass spectrometer (LECO Corp., St. Joseph, MI, USA). The column set consisted of a $30 \mathrm{~m} \times 0.25 \mathrm{~mm} \times 0.25 \mu \mathrm{m}$ primary column with Equity 1 (Sigma-Aldrich, St. Louis, MI, USA) stationary phase and a $2 \mathrm{~m} \times 0.1 \mathrm{~mm} \times 0.1 \mu \mathrm{m}$ secondary column with SolGel-Wax (SGE Analytical Science, Ringwood, Victoria, Australia) stationary phase. The modulation period was $6 \mathrm{~s}$. The following optimized temperature program was used for the separation 


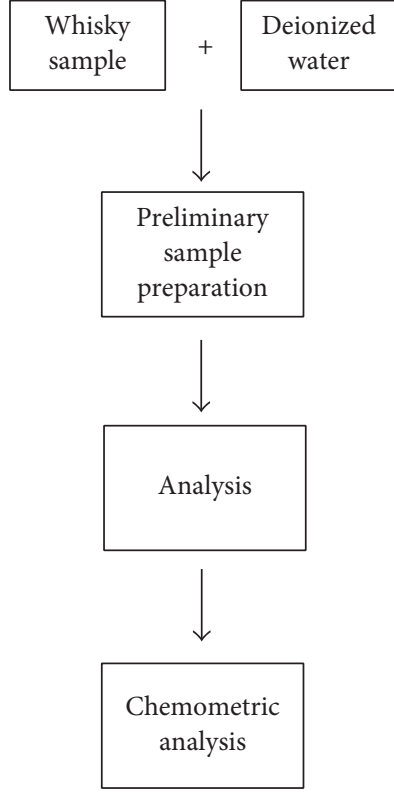

FIGURE 1: General scheme of procedures for sample preparation and analysis.

of the sample: initial temperature of $40^{\circ} \mathrm{C}$ maintained for $3.5 \mathrm{~min}$ and then ramped to $250^{\circ} \mathrm{C}$ and kept for $5 \mathrm{~min}$. The total analysis time was $28 \mathrm{~min} 50 \mathrm{~s}$. The injector was operated at $250^{\circ} \mathrm{C}$ in splitless mode. Helium was used as the carrier gas at a constant flow of $1 \mathrm{~mL} / \mathrm{min}$. The temperature of the ion source was $250^{\circ} \mathrm{C}$, whereas the detector voltage was set to $1600 \mathrm{~V}$. The analyzed $\mathrm{m} / z$ range of ions was $40-400$. The data acquisition rate was 200 spectra/s.

2.4. Electronic Nose Analysis. A HERACLES II Alpha MOS electronic nose based on the technology of ultrafast gas chromatography (Toulouse, France) was used in this study. The device was equipped with a sorption trap, an injection module for gas and liquid samples, HS100 dedicated autosampler, a set of independent columns of different polarity (10 m long nonpolar MXT-5 and medium polar MXT-1701 columns), 2 FID detectors, AlphaSoft V12 software package for HERACLES II with implemented modules for chromatographic and chemometric data analysis and chemical and sensory characterization of detected compounds, and AroChemBase V4 HERACLES V12 library. The autosampler loaded with samples was incubated at $40^{\circ} \mathrm{C}$ for $1200 \mathrm{~s}$, while the syringe temperature was kept at $100^{\circ} \mathrm{C}$. A $2.5 \mathrm{ml}$ aliquot of sample was dispensed for $15 \mathrm{~s}$ at the injector temperature of $200^{\circ} \mathrm{C}$ and the flow rate of carrier gas equaled $30 \mathrm{ml} / \mathrm{min}$. The sample was retained in the sorption trap for $20 \mathrm{~s}$ at $40^{\circ} \mathrm{C}$. The initial temperature of analysis was set to $40^{\circ} \mathrm{C}$ and kept for $2 \mathrm{~s}$. Next, the temperature was raised at a rate of $3^{\circ} \mathrm{C} / \mathrm{s}$ up to $270^{\circ} \mathrm{C}$ and kept for $18 \mathrm{~s}$. Hydrogen was used as the carrier gas.

2.5. Sensory Analysis. Out of the 20 respondents, 10 people were selected for preliminary tests of taste and smell. The general scheme of the election of members of the sensory

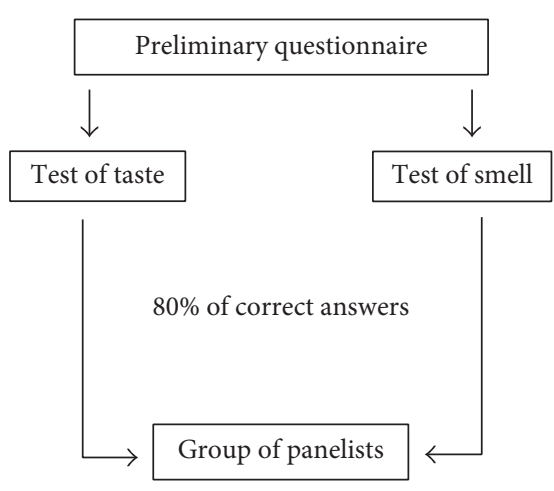

FIGURE 2: Scheme of the election of members of the sensory panel.

panel is presented in Figure 2. Each person gets 5 mixtures to test the taste and 5 mixtures to test the smell. Mixtures used to test the taste include solutions of caffeine, sodium chloride, citric acid, starch, and monosodium glutamate, while mixtures to test the smell include the solution of citral, benzaldehyde, vanillin, eugenol, and 2-methylisoborneol. To qualify for the group of panelists, people had to give $80 \%$ correct answers in each test. From the group of 12 people, 8 people were chosen to take part in the sensory analysis of whisky. The group of panelists included 4 women and 4 men. Samples were analyzed based on smell, taste, and color. The panelists evaluated which type whisky belonged to.

2.6. Chemometric Analysis. The area of compounds identified by the GC $\times$ GC analysis was used as data for chemometric analysis. Compounds present in the volatile fraction of whisky were identified by comparing their spectra with the spectra of fragment ions available in the NIST library. Then, a comparative analysis of different types of whisky was performed using the Matlab software v.7.8 (MathWorks, MA, USA) and the PLS Toolbox software v.6.2 (Eigenvector Research, Manson, WA, USA). The partial least squares with discriminant analysis (PLS-DA) model was created for the discrimination of whisky.

The data obtained from the e-nose analysis were analyzed by means of dedicated software which includes different chemometric methods. Discriminant function analysis (DFA) was used for discrimination of different types of whisky. To compare this technique to other techniques, partial least squares with discriminant analysis (PLS-DA) using Matlab software v.7.8 (MathWorks, MA, USA) and the PLS Toolbox software v.6.2 (Eigenvector Research, Manson, WA, USA) were used.

Results from sensory evaluation were analyzed by using Matlab software v.7.8 (MathWorks, MA, USA) and PLS Toolbox software v.6.2 (Eigenvector Research, Manson, WA, USA). The PLS-DA models were created for the discrimination of whisky.

\section{Results and Discussion}

Whiskies belong to a group of highly aromatic alcohols. This is due to a variety of raw materials used in their 


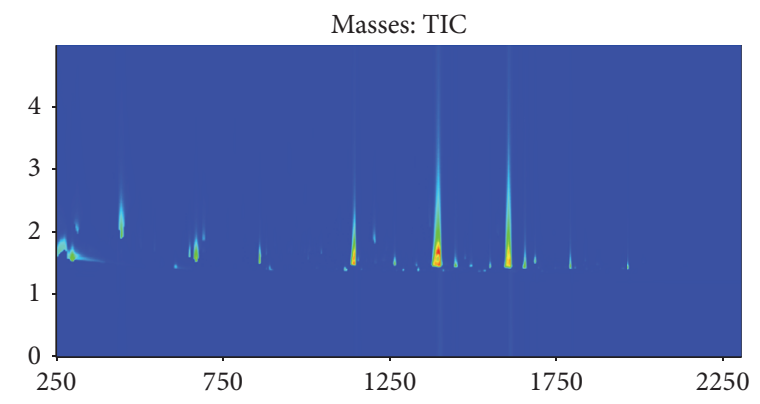

FIGURE 3: Exemplary chromatogram obtained from the analysis of whisky by GC $\times$ GC-TOFMS.

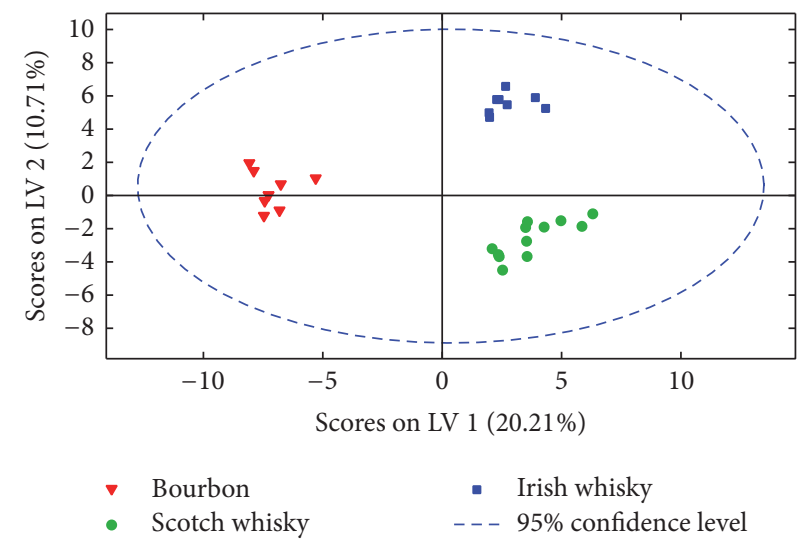

FIGURE 4: Scores plot of the first 2 factors of the PLS-DA model built with the area of the chosen peaks for GC $\times$ GC-TOFMS analysis.

production and to the aging of alcohol in barrels. Whisky includes a variety of compounds from many different groups. Fourteen samples in duplicate were analyzed by using GC $\times$ GC-TOFMS, which allows for the detection of hundreds of compounds. Such large number of compounds can be detected due to the use of two columns of different polarity and cryogenic modulator. Thanks to this, the mixtures of aromatic compounds are separated in two dimensions, thus avoiding the coelution of some compounds. An exemplary chromatogram is shown in Figure 3. Among the samples were 4 bourbons, 6 types of Scotch whisky, and 4 Irish whiskies. From hundreds of compounds, 119 compounds were used for data analysis (Table 1). To select such compounds, the retention times and spectra of fragment ions of all detected compounds were compared with the NIST library. In each case, the compounds were considered to have been identified if the similarity of their spectra to the spectra found in NIST library was at least $85 \%$ and if the signal-to-noise $(\mathrm{s} / \mathrm{n})$ ratio was higher than 100. For data, PLS-DA (Figure 4) was used. Autoscale and SNV algorithm were used for preprocessing, and a Venetian blind was used for cross-validation. PLSDA allows for the discrimination of samples by type, which includes different botanical origins and types of production. As can be seen in Table 2, showing confusion matrices and confusion tables, both for calibration and for cross-validation data, all samples were classified correctly.
A quick tool for assessing the quality of the whisky may be an electronic nose. An e-nose based on Fast-GC was used for the discrimination of whisky according to the type. Six samples of Scotch whisky, four samples of Irish whisky, and four samples of bourbon from four different batches were analyzed in triplicate. For data analysis, the area of the peaks was used as input data. In the case of Fast-GC analysis, a smaller number of compounds can be detected than in the case of GC $\times$ GC analysis. This number is connected with the use of shorter column and with the coelution of some compounds, which cannot be separated in one dimension. An exemplary chromatogram is shown in Figure 5. Due to the presence of the implemented software, DFA was used for data analysis. All groups were discriminated by type. In Table 3, DFA was used for data analysis (Figure 6). All four groups of whisky were discriminated according to botanical origin and the way of production by DFA analysis. The verification of this method was obtained by calculation of the Euclidean distances between groups and pattern discrimination indices which are shown in Table 3. The smallest distance (10.59) is between the Irish and Scotch whisky. This is because the same type of raw material is used for the production of both types of whisky. The variables used as input data for DFA analysis, namely, the most discriminant peak areas for specific compounds, were presented in Figure 7 and the names of selected chemical compounds were presented in Table 4. 


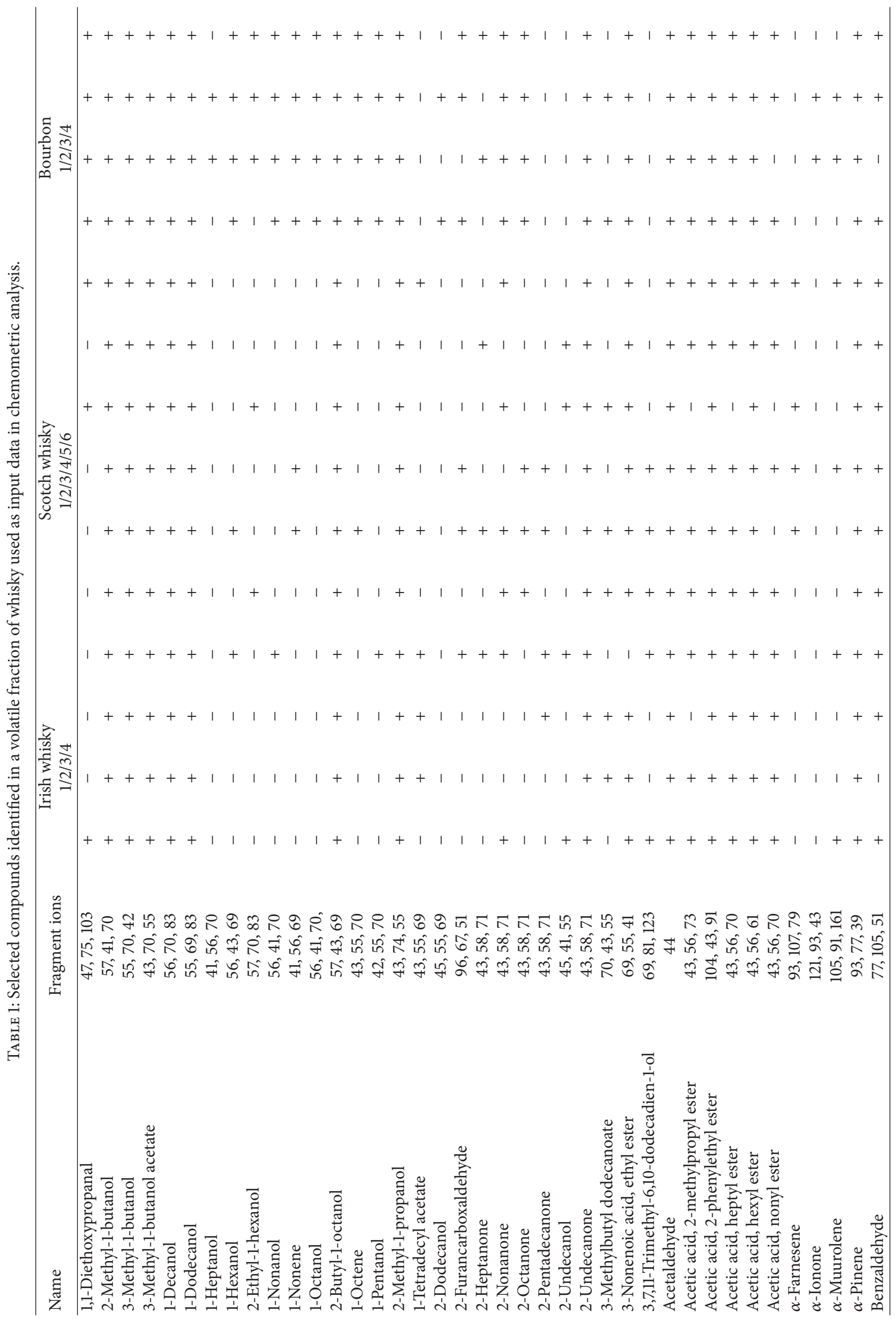




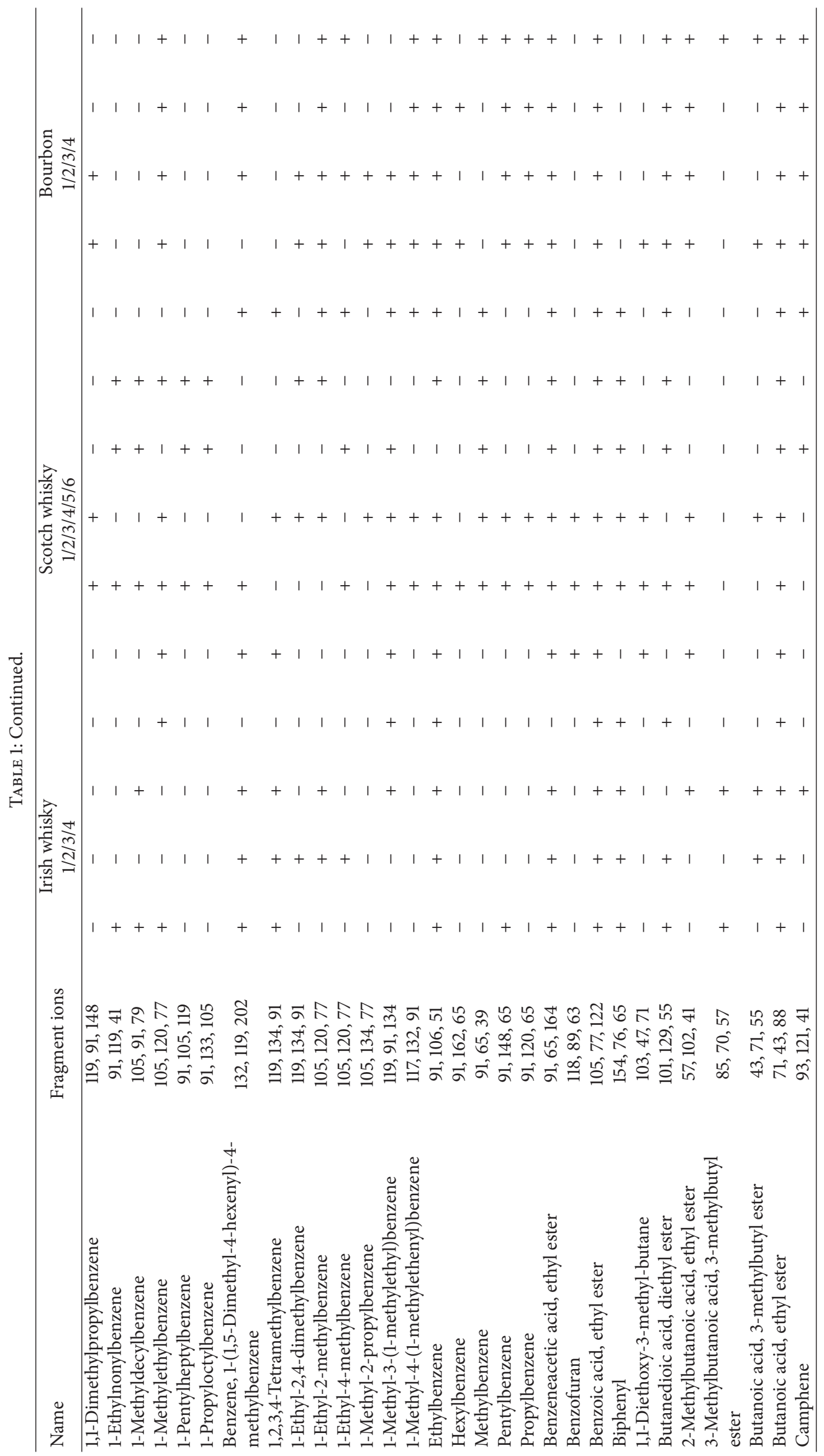




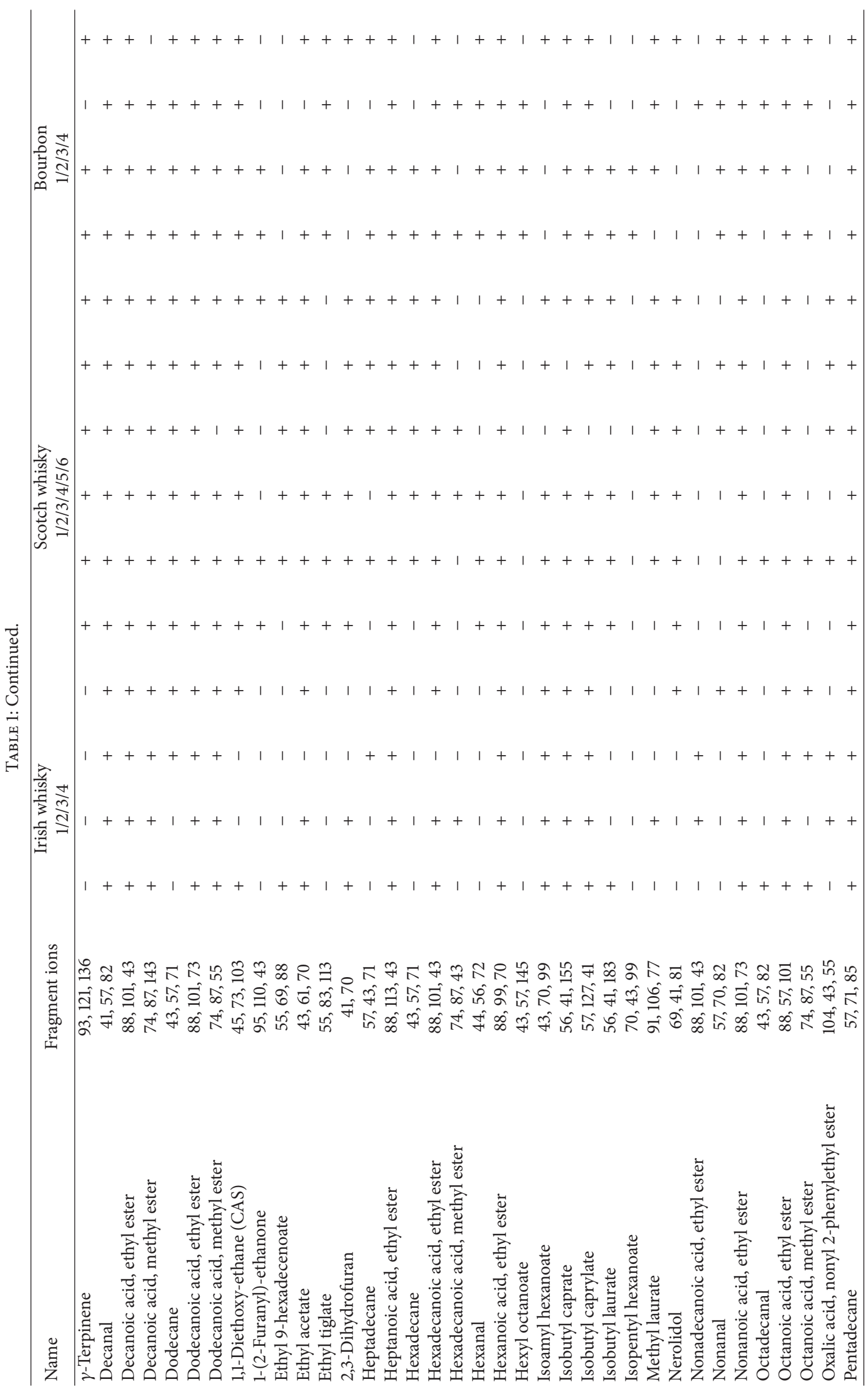




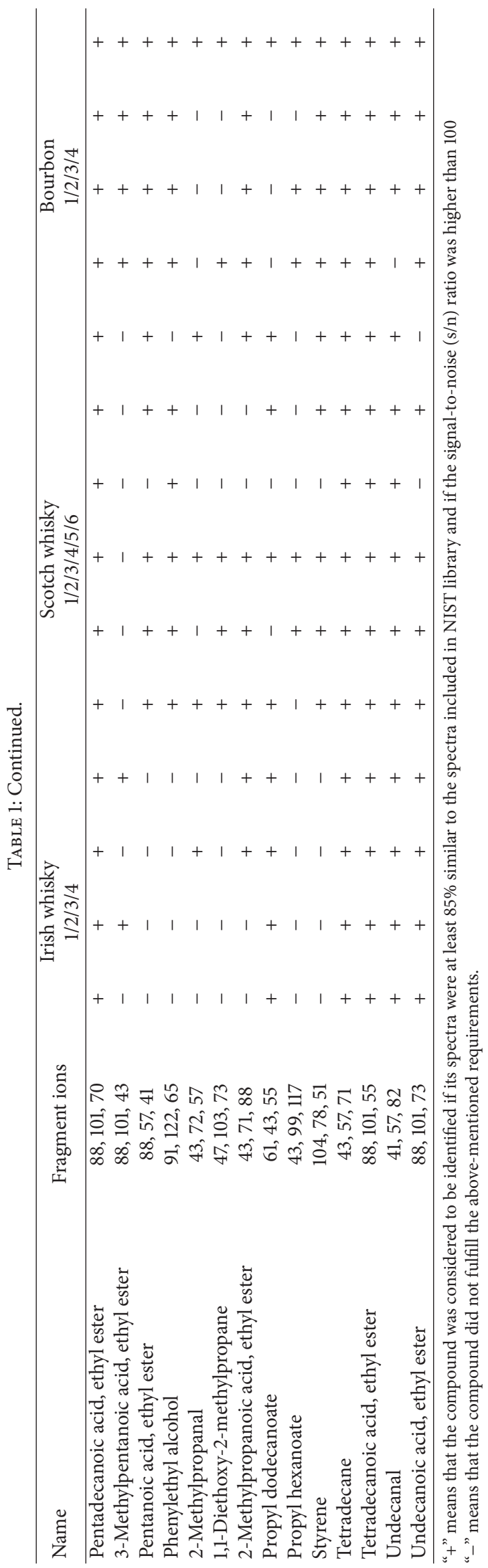


TABLE 2: Confusion matrices and confusion tables for results obtained by the use of GC $\times$ GC-TOFMS, e-nose, and sensory analysis.

\begin{tabular}{|c|c|c|c|c|c|c|c|c|c|c|c|c|}
\hline & \multicolumn{4}{|c|}{ GC $\times$ GC-TOFMS } & \multicolumn{4}{|c|}{ E-nose } & \multicolumn{4}{|c|}{ Sensory analysis } \\
\hline & \multicolumn{12}{|c|}{ Model results } \\
\hline & \multicolumn{12}{|c|}{ Confusion matrix } \\
\hline Class & $\mathrm{TP}$ & $\mathrm{FP}$ & TN & $\mathrm{FN}$ & $\mathrm{TP}$ & $\mathrm{FP}$ & $\mathrm{TN}$ & $\mathrm{FN}$ & $\mathrm{TP}$ & FP & $\mathrm{TN}$ & $\mathrm{FN}$ \\
\hline Bourbon & 1.000 & 0.000 & 1.000 & 0.000 & 1.000 & 0.000 & 1.000 & 0.000 & 1.000 & 0.000 & 1.000 & 0.000 \\
\hline Scotch & 1.000 & 0.000 & 1.000 & 0.000 & 1.000 & 0.000 & 1.000 & 0.000 & 1.000 & 0.000 & 1.000 & 0.000 \\
\hline \multirow[t]{2}{*}{ Irish } & 1.000 & 0.000 & 1.000 & 0.000 & 1.000 & 0.000 & 1.000 & 0.000 & 1.000 & 0.000 & 1.000 & 0.000 \\
\hline & \multicolumn{12}{|c|}{ Confusion table } \\
\hline Predicted as & \multicolumn{2}{|c|}{ Bourbon } & Scotch & Irish & \multicolumn{2}{|c|}{ Bourbon } & Scotch & Irish & \multicolumn{2}{|c|}{ Bourbon } & Scotch & Irish \\
\hline Bourbon & \multicolumn{2}{|c|}{8} & 0 & 0 & \multicolumn{2}{|c|}{48} & 0 & 0 & \multicolumn{2}{|c|}{4} & 0 & 0 \\
\hline Scotch & \multicolumn{2}{|c|}{0} & 12 & 0 & \multicolumn{2}{|c|}{0} & 72 & 0 & \multicolumn{2}{|c|}{0} & 6 & 0 \\
\hline Irish & \multicolumn{2}{|c|}{0} & 0 & 8 & \multicolumn{2}{|c|}{0} & 0 & 48 & \multicolumn{2}{|c|}{0} & 0 & 4 \\
\hline & \multicolumn{12}{|c|}{ Cross-validation results } \\
\hline & \multicolumn{12}{|c|}{ Confusion matrix } \\
\hline Class & $\mathrm{TP}$ & FP & $\mathrm{TN}$ & $\mathrm{FN}$ & $\mathrm{TP}$ & FP & $\mathrm{TN}$ & $\mathrm{FN}$ & $\mathrm{TP}$ & FP & $\mathrm{TN}$ & $\mathrm{FN}$ \\
\hline Bourbon & 1.000 & 0.000 & 1.000 & 0.000 & 1.000 & 0.000 & 1.000 & 0.000 & 0.250 & 0.300 & 0.700 & 0.000 \\
\hline Scotch & 1.000 & 0.000 & 1.000 & 0.000 & 1.000 & 0.000 & 1.000 & 0.000 & 0.500 & 0.375 & 0.725 & 0.000 \\
\hline \multirow[t]{2}{*}{ Irish } & 1.000 & 0.000 & 1.000 & 0.000 & 1.000 & 0.000 & 1.000 & 0.000 & 0.250 & 0.300 & 0.700 & 0.000 \\
\hline & \multicolumn{12}{|c|}{ Confusion table } \\
\hline Predicted as & \multicolumn{2}{|c|}{ Bourbon } & Scotch & Irish & \multicolumn{2}{|c|}{ Bourbon } & Scotch & Irish & \multicolumn{2}{|c|}{ Bourbon } & Scotch & Irish \\
\hline Bourbon & \multicolumn{2}{|c|}{8} & 0 & 0 & \multicolumn{2}{|c|}{48} & 0 & 0 & \multicolumn{2}{|c|}{1} & 1 & 2 \\
\hline Scotch & \multicolumn{2}{|c|}{0} & 12 & 0 & \multicolumn{2}{|c|}{0} & 72 & 0 & & & 3 & 1 \\
\hline Irish & & & 0 & 8 & & & 0 & 48 & & & 2 & 1 \\
\hline
\end{tabular}

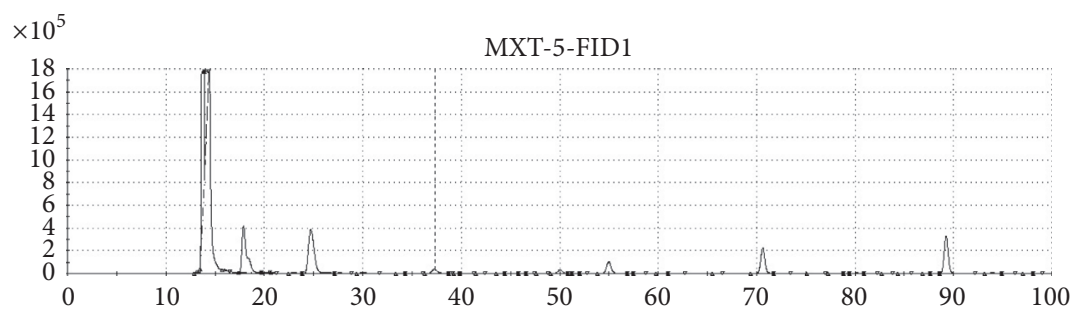

$\mathrm{RT}=37.30 \mathrm{sec}$

Intensity $=35,862.53$

(a)

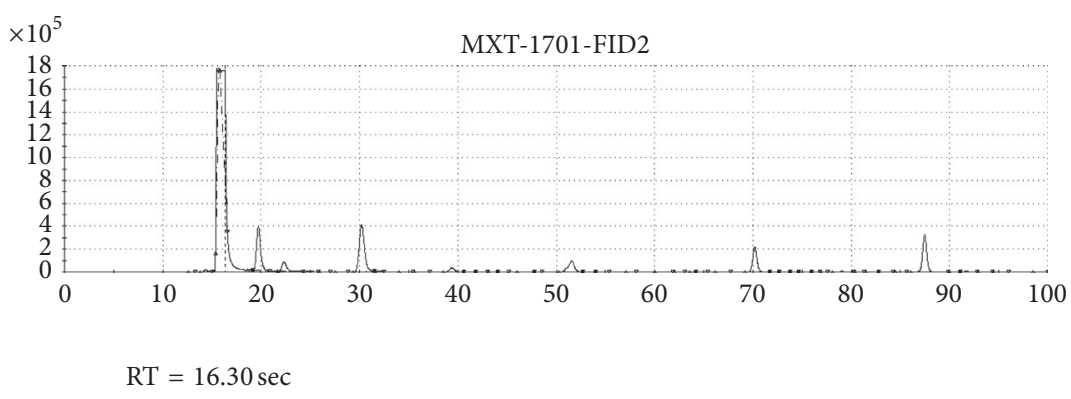

Intensity $=1,765,907.28$

(b)

FIGURE 5: Exemplary chromatogram obtained from the analysis of whisky by e-nose using Fast-GC-A. 


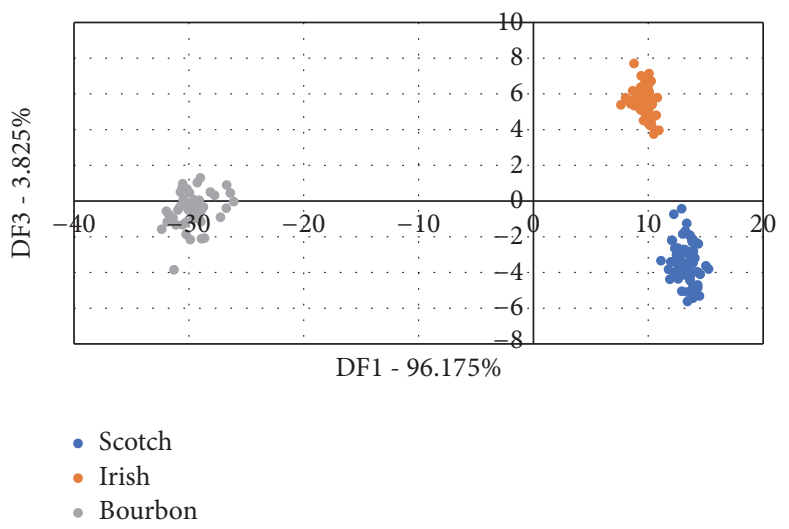

FIGURE 6: Scores plot of the first 2 factors of the DFA model for e-nose analysis of whiskies according to their type.

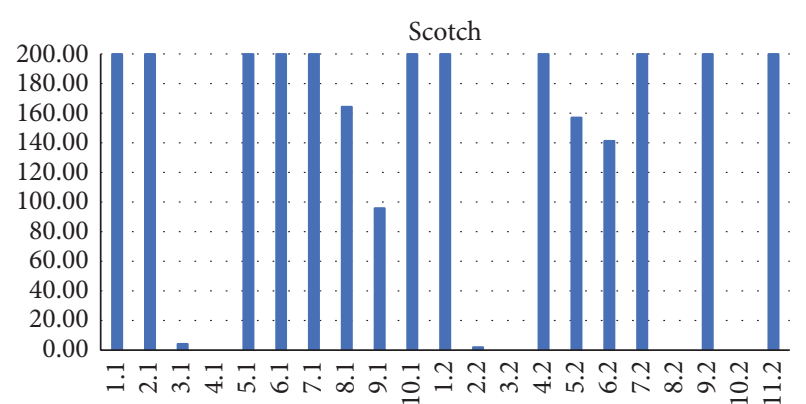

(a)

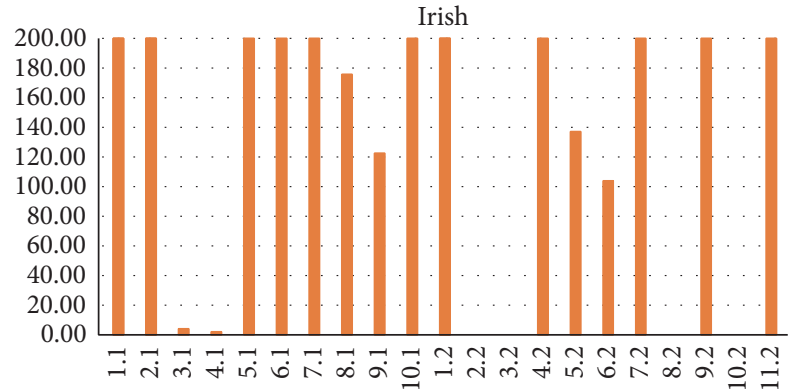

(b)

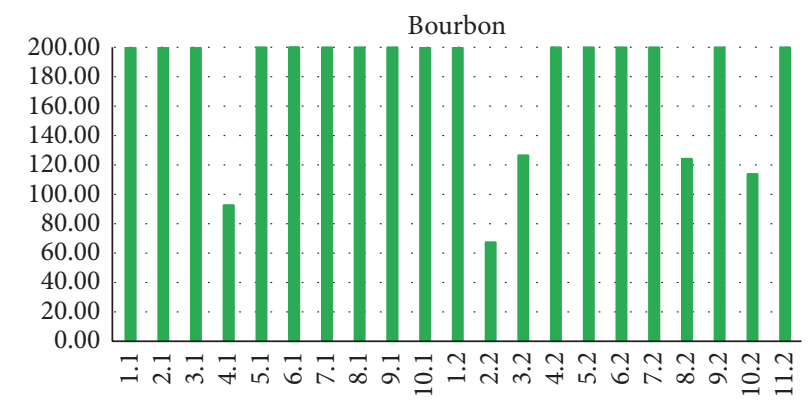

(c)

Figure 7: Mean bar graphs of selected peak areas used as raw data in chemometrics representing key chemical compounds, which are important for discrimination of (a) Scotch whisky, (b) Irish whisky, and (c) bourbon.

TABLE 3: Calculated values of Euclidean distances and pattern discrimination indices between groups of whisky samples according to DFA results.

\begin{tabular}{lccc}
\hline Relation between groups & Distances & $\begin{array}{c}\text { Pattern } \\
\text { discrimination } \\
\text { index (\%) }\end{array}$ \\
\hline Scotch & Bourbon & 421800.88 & 94.59 \\
Scotch & Irish & 48167.83 & 10.59 \\
Irish & Bourbon & 419440.47 & 89.00 \\
\hline
\end{tabular}

Substances present in the sample were identified on the basis of comparison of calculated linear temperature-programmed retention indices (LTPRI) with indices included in the database. To compare this technique to the others, PLS-DA was used for data analysis (Figure 8). As input data, the areas of all detected peaks were used as variables. Preprocessing and cross-validation methods were the same as in the case of GC $\times$ GC analysis. As can be seen in Table 2, all samples were classified correctly.

During the sensory analysis, the panelists evaluated which type the tested whisky belonged to. PLS-DA was used for data analysis (Figure 9). Preprocessing and crossvalidation methods were the same as in the case of other analyses. None of the groups was discriminated correctly, which can be seen in Table 2. However, this type of analysis 
TABLE 4: Key chemical compounds (variables), which are important for sample discrimination.

\begin{tabular}{|c|c|c|c|c|}
\hline $\begin{array}{l}\text { Number of } \\
\text { variables-column } \\
\text { number }\end{array}$ & Name of the compound & Scotch & Irish & Bourbon \\
\hline $1-1$ & 2-Propanol & + & + & + \\
\hline $2-1$ & n-Butanol & + & + & + \\
\hline $3-1$ & Furfural & + & + & + \\
\hline $4-1$ & Ethyl isovalerate & - & + & + \\
\hline $5-1$ & Alpha-pinene & + & + & + \\
\hline $6-1$ & Decanal & + & + & + \\
\hline $7-1$ & Eugenol & + & + & + \\
\hline $8-1$ & Geosmin & + & + & + \\
\hline $9-1$ & Gamma-decalactone & + & + & + \\
\hline $10-1$ & 12-Methyltridecanal & + & + & + \\
\hline $1-2$ & n-Butanol & + & + & + \\
\hline $2-2$ & Furfural & + & - & + \\
\hline $3-2$ & 1-Octanol & - & - & + \\
\hline $4-2$ & Decanal & + & + & + \\
\hline $5-2$ & 2,4-Nonadienal & + & + & + \\
\hline $6-2$ & Phenylethyl acetate & + & + & + \\
\hline $7-2$ & $(\mathrm{E}, \mathrm{E})-2,3$-Decadienal & + & + & + \\
\hline $8-2$ & 4-Vinylguaiacol & - & - & + \\
\hline $9-2$ & Geosmin & + & + & + \\
\hline $10-2$ & Gamma-nonalactone & - & - & + \\
\hline $11-2$ & Gamma-decalatone & + & + & + \\
\hline
\end{tabular}

"+" means that the compound was considered as variable for the chosen group.

"-" means that the compound was not considered as variable for the chosen group.

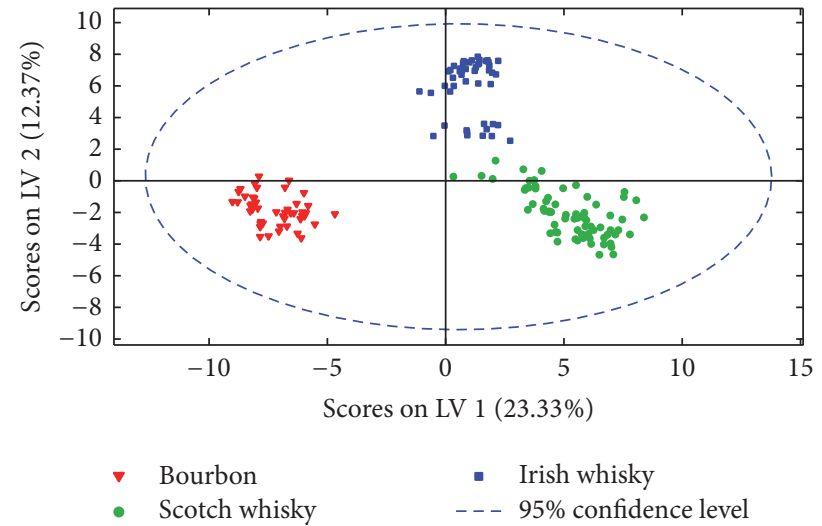

FIGURE 8: Scores plot of the first 2 factors of the PLS-DA model built with the area of the chosen peaks for e-nose analysis.

showed the preferences of consumers, who evaluated the taste and smell of Scotch whisky as the most desirable.

The classification results, both for calibration and for cross-validation data for all techniques, are compared in Table 5. Sensitivity is defined as the proportion of samples belonging to a given class that are correctly classified in that class. Specificity is the proportion of samples not belonging

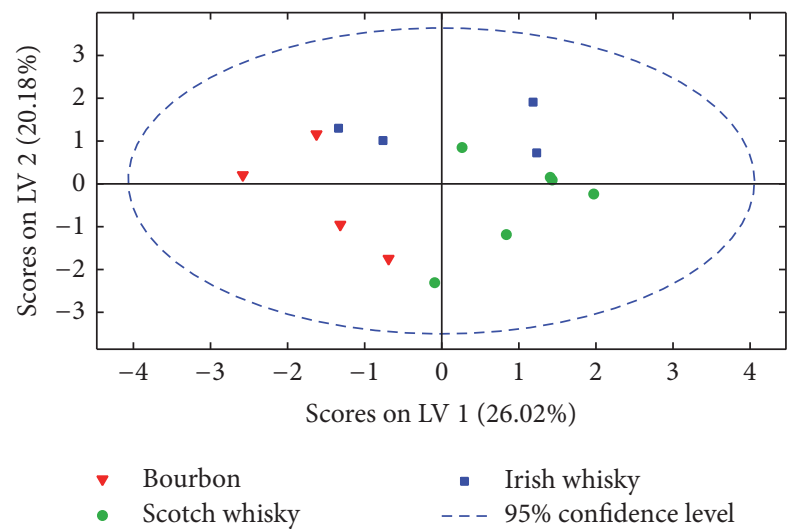

FIGURE 9: Scores plot of the first 2 factors of the PLS-DA model built for sensory analysis.

to a given class that are correctly rejected in that class. Classification error is the proportion of samples incorrectly classified.

$\mathrm{GC} \times \mathrm{GC}$ and e-nose analysis allow for discrimination of whisky due to the botanical origin and the way of production in contrast to sensory analysis. The quickest analysis was obtained by using e-nose. The most complex analysis of 
TABLE 5: Classification results for Scotch whisky, bourbon, and Irish whisky.

\begin{tabular}{|c|c|c|c|c|c|c|c|c|c|}
\hline \multirow{2}{*}{ Modeled class } & \multicolumn{3}{|c|}{$\mathrm{GC} \times \mathrm{GC}$} & \multicolumn{3}{|c|}{ E-nose } & \multicolumn{3}{|c|}{ Sensory analysis } \\
\hline & Bourbon & Scotch & Irish & Bourbon & Scotch & Irish & Bourbon & Scotch & Irish \\
\hline $\begin{array}{l}\text { Sensitivity (Cal) } \\
\text { (C) }\end{array}$ & 1.000 & 1.000 & 1.000 & 1.000 & 1.000 & 1.000 & 1.000 & 1.000 & 1.000 \\
\hline Specificity (Cal) & 1.000 & 1.000 & 1.000 & 1.000 & 0.990 & 1.000 & 0.900 & 0.875 & 1.000 \\
\hline Class. err. (Cal) & 0.000 & 0.000 & 0.000 & 0.000 & 0.005 & 0.000 & 0.050 & 0.062 & 0.000 \\
\hline Sensitivity $(\mathrm{CV})$ & 1.000 & 1.000 & 1.000 & 1.000 & 1.000 & 1.000 & 0.250 & 0.500 & 0.500 \\
\hline Specificity (CV) & 1.000 & 1.000 & 1.000 & 1.000 & 0.990 & 0.992 & 0.700 & 0.625 & 0.800 \\
\hline Class. err. (CV) & 0.000 & 0.000 & 0.000 & 0.000 & 0.005 & 0.004 & 0.525 & 0.438 & 0.350 \\
\hline
\end{tabular}

TABLE 6: Comparison of GC $\times$ GC-TOFMS e-nose based on Fast-GC and sensory analysis for whisky samples discrimination.

\begin{tabular}{|c|c|c|c|}
\hline Type of analysis & $\begin{array}{c}\text { Discrimination of whisky } \\
\text { due to the type }\end{array}$ & Advantages & Disadvantages \\
\hline GC $\times$ GC-TOFMS & Correct & $\begin{array}{l}\text { It allows for precise } \\
\text { examination of the } \\
\text { composition of the matrix. }\end{array}$ & $\begin{array}{l}\text { It is time-consuming and } \\
\text { expensive. }\end{array}$ \\
\hline E-nose based on Fast-GC & Correct & $\begin{array}{l}\text { It allows for a partial } \\
\text { analysis of the composition } \\
\text { of the matrix. It is quick } \\
\text { and relatively cheap. The } \\
\text { software includes } \\
\text { chemometric analysis. }\end{array}$ & $\begin{array}{l}\text { It does not allow for precise } \\
\text { examination of the } \\
\text { composition of the matrix. }\end{array}$ \\
\hline Sensory analysis & Incorrect & $\begin{array}{l}\text { It allows for quality } \\
\text { assessment due to } \\
\text { consumer preferences. It is } \\
\text { relatively cheap. }\end{array}$ & $\begin{array}{l}\text { It is subjective and does not } \\
\text { allow for discrimination of } \\
\text { whisky based on the type. }\end{array}$ \\
\hline
\end{tabular}

matrices was obtained by using GC $\times$ GC analysis. However, $\mathrm{GC} \times \mathrm{GC}$ analysis is too expensive to use for regular analysis of whisky. Sensory analysis was too subjective to obtain a correct classification of whisky by type, but it was the only one allowing for an evaluation of consumer preferences. The comparison of GC $\times$ GC-TOFMS, e-nose based on Fast-GC, and sensory analysis is shown in Table 6.

\section{Conclusion}

To sum up, the electronic nose based on the technology of ultrafast gas chromatography, comprehensive two-dimensional gas chromatography, and sensory evaluation was applied for distinguishing between selected whiskies of different botanical origins and different ways of production. GC $\times$ GC-TOFMS allowed for discrimination of whisky according to type. Apart from this, it allowed for identification of hundreds of compounds. Unfortunately, analysis of whisky by means of this technique is too expensive and it will take too long for it to be a routine evaluation of whisky. Sensory evaluation allowed access to people's preferences. It is a good tool for quality assessment but it does not allow for discrimination of whisky by type. Because of people, it can be also too subjective to ensure correct evaluation. An e-nose based on Fast-GC allows for good discrimination of whisky by type. Besides, it is not as subjective as sensory evaluation and the analysis is cheaper and less time-consuming than in the case of gas chromatography. This technique could be used for rapid and routine classification in industrial production, which will be the subject of further studies.

\section{Competing Interests}

The authors declare that there are no competing interests regarding the publication of this paper.

\section{Acknowledgments}

The authors acknowledge the financial support for this study by Grant no. 2012/05/B/ST4/01984 from the National Science Centre of Poland. The received funding did not lead to any competing interests regarding the publication of this manuscript.

\section{References}

[1] Regulation (EC) No 110/2008 of the European Parliament and the Council of 15 January 2008 on the definition, description, presentation, labelling and protection of geographical indications of spirit drinks and repealing Council Regulation (EEC) No 1576/89.

[2] N. Christoph and C. Bauer-Christoph, "Vodka," in Flavours and Fragrances Chemistry, Bioprocessing and Sustainability, R. G. Berger, Ed., p. 231, Springer, Berlin, Germany, 2007.

[3] C. N. Rhodes, K. Heaton, I. Goodall, and P. A. Brereton, "Gas chromatography carbon isotope ratio mass spectrometry 
applied to the detection of neutral alcohol in Scotch whisky: an internal reference approach," Food Chemistry, vol. 114, no. 2, pp. 697-701, 2009.

[4] C. Bamforth, "Whisky analysis," in Whisky: Technology, Production and Marketing, I. Russell and G. Stewart, Eds., pp. 275-306, Elsevier, London, UK, 2003.

[5] R. Ralph, "Production of American whiskies: bourbon, corn, rye and Tennessee," in The Alcohol Textbook, K. A. Jacques, T. P. Lyons, and D. R. Kelsall, Eds., pp. 275-285, Nottingham University Press, Nottingham, UK, 2003.

[6] S. Reigler, Kentucky Bourbon Country: The Essential Travel Guide, The University Press of Kentucky, Lexington, Ky, USA, 2013.

[7] P. J. S. Barbeira and N. R. Stradiotto, "Anodic stripping voltammetric determination of $\mathrm{Zn}, \mathrm{Pb}$ and $\mathrm{Cu}$ traces in whisky samples," Fresenius' Journal of Analytical Chemistry, vol. 361, no. 5, pp. 507-509, 1998.

[8] M. P. Martí, O. Busto, J. Guasch, and R. Boqué, "Electronic noses in the quality control of alcoholic beverages," TrAC - Trends in Analytical Chemistry, vol. 24, no. 1, pp. 57-66, 2005.

[9] J. S. Garcia, B. G. Vaz, Y. E. Corilo et al., "Whisky analysis by electrospray ionization-Fourier transform mass spectrometry," Food Research International, vol. 51, no. 1, pp. 98-106, 2013.

[10] A. G. Mignani, L. Ciaccheri, B. Gordillo et al., "Identifying the production region of single-malt Scotch whiskies using optical spectroscopy and pattern recognition techniques," Sensors and Actuators, B: Chemical, vol. 171-172, pp. 458-462, 2012.

[11] P. C. Ashok, B. B. Praveen, and K. Dholakia, "Near infrared spectroscopic analysis of single malt Scotch whisky on an optofluidic chip," Optics Express, vol. 19, no. 23, pp. 2298222992, 2011.

[12] R. I. Aylott, A. H. Clyne, A. P. Fox, and D. A. Walker, "Analytical strategies to confirm Scotch whisky authenticity," Analyst, vol. 119, no. 8, pp. 1741-1746, 1994.

[13] T. Adam, E. Duthie, and J. Feldmann, "Investigations into the use of copper and other metals as indicators for the authenticity of scotch whiskies," Journal of the Institute of Brewing, vol. 108, no. 4, pp. 459-464, 2002.

[14] I. G. Parker, S. D. Kelly, M. Sharman, M. J. Dennis, and D. Howie, "Investigation into the use of carbon isotope ratios (13C/12C) of Scotch whisky congeners to establish brand authenticity using gas chromatography-combustion-isotope ratio mass spectrometry," Food Chemistry, vol. 63, no. 3, pp. 423-428, 1998.

[15] K.-Y. M. Lee, A. Paterson, J. R. Piggott, and G. D. Richardson, "Sensory discrimination of blended Scotch whiskies of different product categories," Food Quality and Preference, vol. 12, no. 2, pp. 109-117, 2001.

[16] M. Śliwińska, P. Wiśniewska, T. Dymerski, J. Namieśnik, and W. Wardencki, "Food analysis using artificial senses," Journal of Agricultural and Food Chemistry, vol. 62, no. 7, pp. 1423-1448, 2014.

[17] Alpha MOS, http://www.alpha-mos.com/pdf/en/instruments/ electronic_nose/Alpha-MOS_HERACLES_Electronic_Nose.pdf.

[18] P. Wiśniewska, M. Śliwińska, T. Dymerski, W. Wardencki, and J. Namieśnik, "Qualitative characteristics and comparison of volatile fraction of vodkas made from different botanical materials by comprehensive two-dimensional gas chromatography and the electronic nose based on the technology of ultra-fast gas chromatography," Journal of the Science of Food and Agriculture, vol. 97, no. 4, pp. 1316-1325, 2017. 

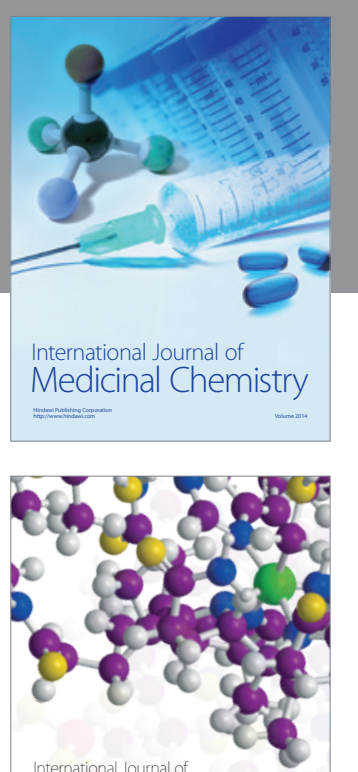

Carbohydrate Chemistry

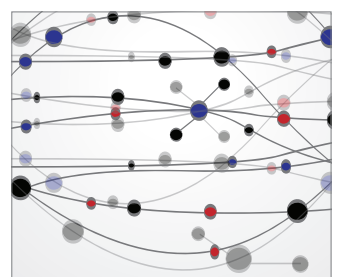

The Scientific World Journal
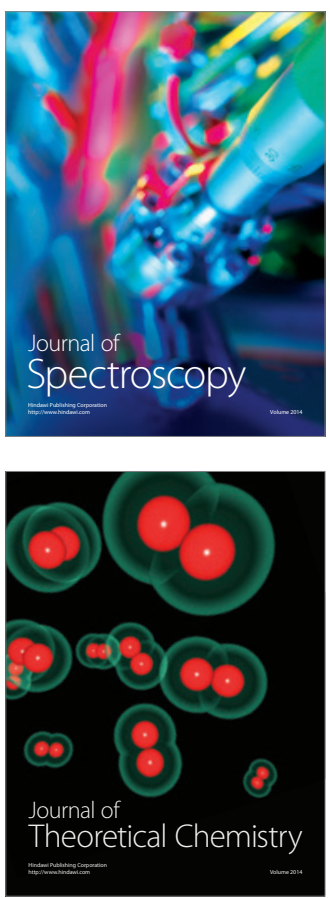
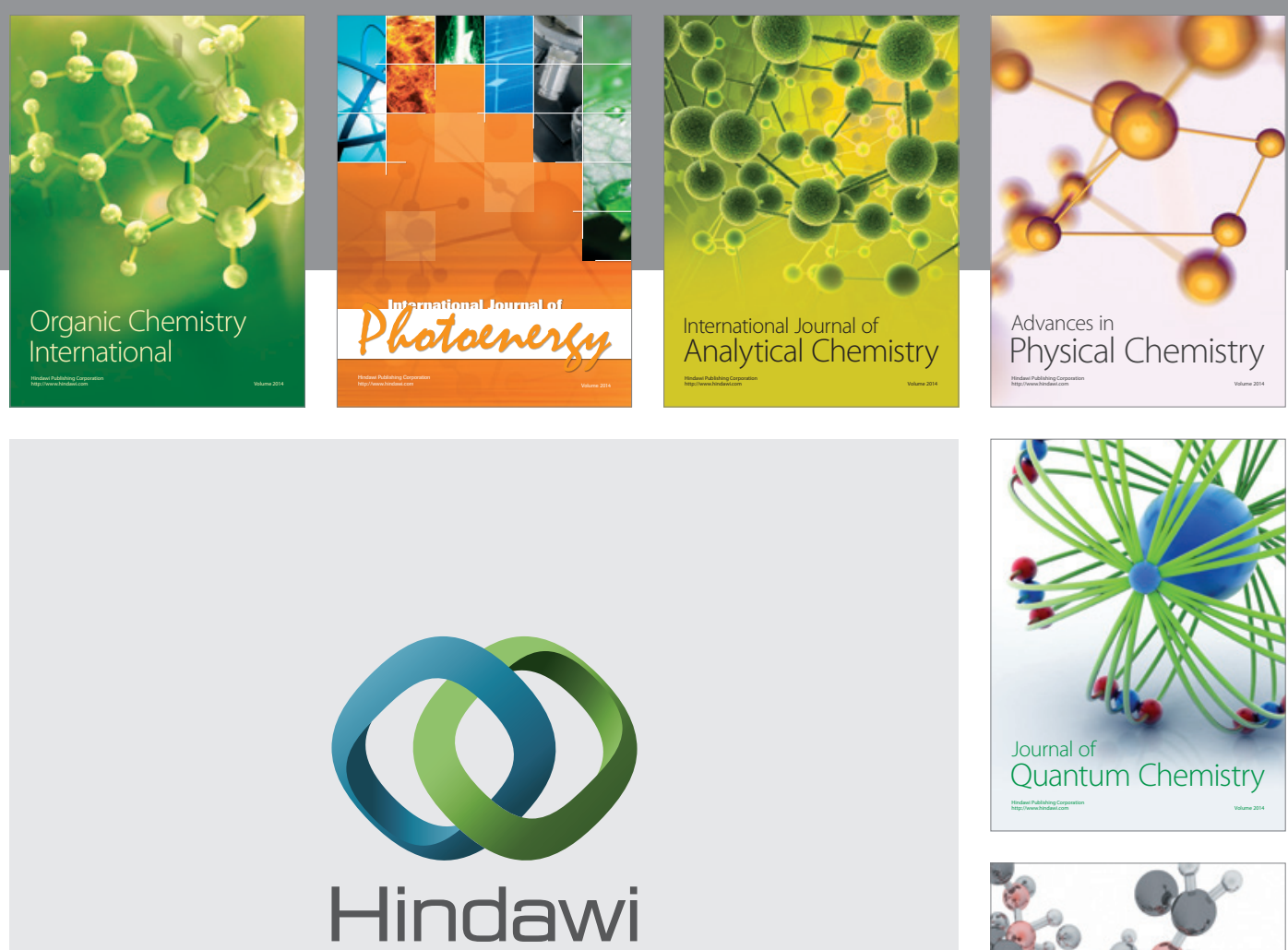

Submit your manuscripts at

https://www.hindawi.com

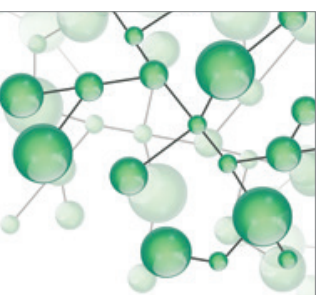

International Journal of

Inorganic Chemistry
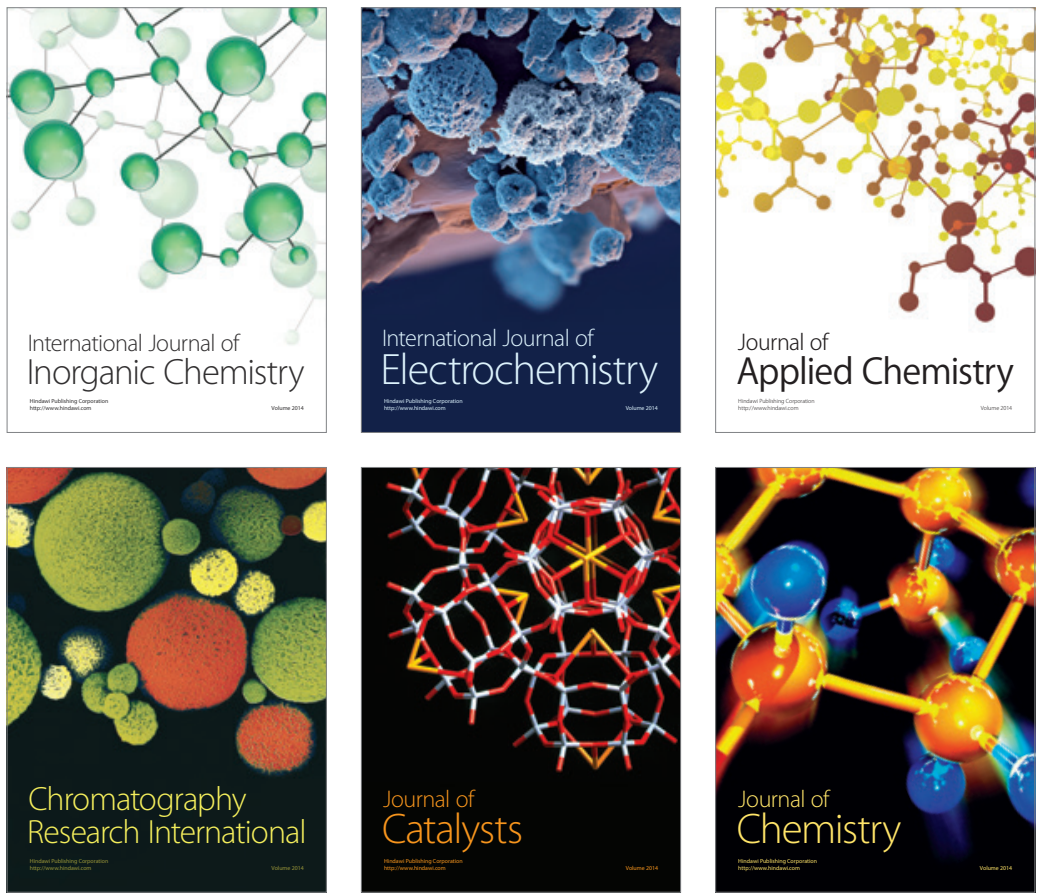

Journal of

Applied Chemistry
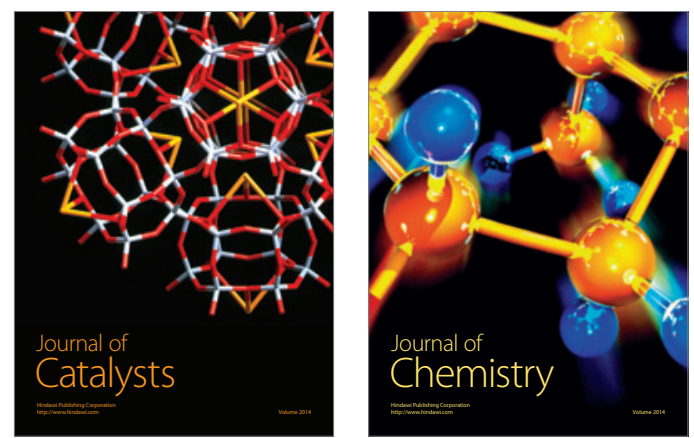
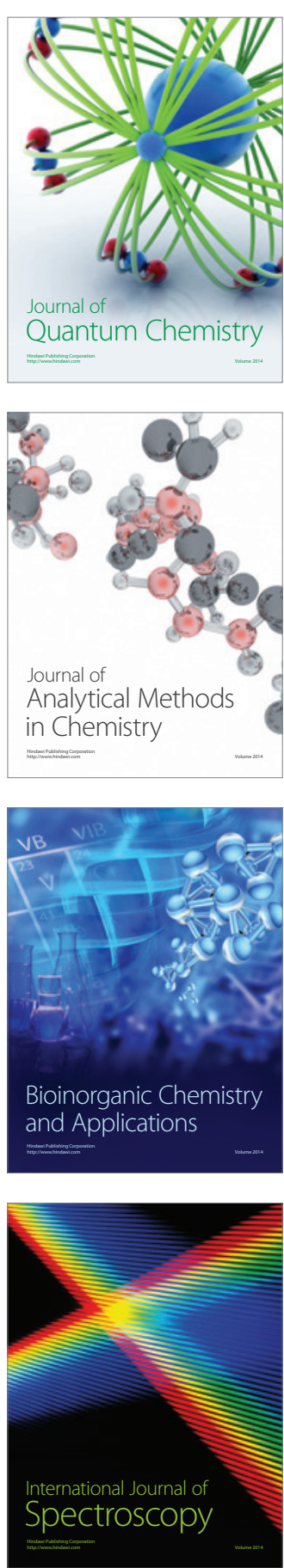